Article

\title{
Sustainability Transitions and the Spatial Interface: Developing Conceptual Perspectives
}

\author{
Meike Levin-Keitel ${ }^{1,2, *(\mathbb{D})}$, Tanja Mölders ${ }^{2,3}$, Frank Othengrafen ${ }^{1,2}$ (D) and Jens Ibendorf ${ }^{2}$ \\ 1 Institute of Environmental Planning, Leibniz Universität Hannover, 30419 Hannover, Germany; \\ othengrafen@umwelt.uni-hannover.de \\ 2 Research Center TRUST-Transdisciplinary Rural and Urban Transformation, Leibniz Universität Hannover, \\ 30419 Hannover, Germany; t.moelders@archland.uni-hannover.de (T.M.); \\ ibendorf@trust.uni-hannover.de (J.I.) \\ 3 Forum for GenderCompetence of Architecture I Landscape I Planning (gender_archland), \\ Leibniz Universität Hannover, 30419 Hannover, Germany \\ * Correspondence: levin@umwelt.uni-hannover.de; Tel.: +49-511-762-3176
}

Received: 30 April 2018; Accepted: 31 May 2018; Published: 5 June 2018

check for updates

\begin{abstract}
Sustainability transitions research lacks a crucial perspective: the spatial dimension. The interrelations between space and sustainability transition processes are thus underexposed. The spatial dimension is, of course, implicitly addressed in transition research but it often remains unclear which spatial concept is used and how the spatial conditions are embedded in the transition processes. This paper approaches the problem in two steps: (1) analysing the various understandings of transitions research and their implications for different spatial concepts relating to spatial sustainability transition; and (2) focusing on different spatial concepts (from a positivist mode to relational and socio-cultural approaches) and their reflections in different disciplines of social, natural and technical sciences as well as in practice. By identifying the links between sustainable transition approaches on the one hand and spatial conceptualizations on the other hand, this paper aims at deepening both the spatial perspective and the understanding of sustainable transition research. The results of this paper are three conceptual perspectives wherein space or spatial conceptualizations can provide added value for sustainability transition research in inter- and transdisciplinary modes. These three perspectives include (1) space as a "bridging concept," (2) space as a "normative concept," and (3) space as an "approach to action."
\end{abstract}

Keywords: sustainability; physical space; socio-cultural space; relational space; inter- and transdisciplinarity; conceptual perspectives

\section{Introduction}

In our understanding, sustainability transitions are, per se, related to space and take place within specific and given geographical contexts [1] (p. 2). However, until now, sustainability research has mainly followed a domain-based approach (e.g., energy, water, etc.) in which space or spatial conceptualizations only play a minor role [1,2]. Space is, of course, increasingly considered in sustainability transition research [2-8] but this encompasses such concepts as location, uneven development, scaling and (local) embeddedness. Sustainability transitions are neither considered in an inter-sectoral way nor in a given geographical context. Additionally, transition research often uses implicit spatial concepts or approaches. This becomes obvious, for example, with regard to the Sustainable Development Goals (SDGs), including clean water and sanitation, affordable and clean energy, sustainable cities and communities, climate action, etc. These goals are situated in specific spatial contexts but do not explicitly pronounce any spatial dimensions. As a consequence, it remains unclear which 
spatial understandings or concepts sustainability research is based on. This "spatial blindness" increases factual challenges at the local and regional levels, seen both as a spatial-physical space where nature, (new) technologies, settlements, buildings or infrastructures have to be developed, tested and constructed, as well as socio-cultural and political environments where different actors, institutions and political arenas negotiate sustainability and aim to implement sustainable practices.

The aim of this paper is thus to broaden the spatial perspective on and understanding of sustainability transition research. Therefore, shortcomings in existing conceptual frameworks in transition research will be identified [1] (pp. 2-3) and complemented by introducing different understandings and conceptualizations of space [9-11]. The idea is to develop a more differentiated picture of the dynamic interrelations between transition processes on the one hand and spatial perspectives on the other hand, including physical spaces, actors, institutional frameworks, symbolic meanings and ideologies. Using space as a problem-oriented concept that encompasses both physical structures and social, cultural and institutional changes, we will offer conceptual perspectives for a broader understanding of sustainability transitions.

To do so, this theoretically oriented paper is based on extensive literature research, including two electronic databases: Web of Knowledge and Scopus. The literature search concentrated on English-speaking papers published in peer-reviewed journals; further eligible papers were identified from following-up references. Methodologically, the literature survey first focused on transition research, its goals and concepts; and, in a second step, on the spatial contexts and understandings of sustainability transitions. In the first stage, the search for sustainability transition focused on a selected review of some of its most prominent recent literature including the following key words or combination of key words: "transition," "transformation," "urban," "regional," "sustainability," and "transition research." In the selection and analysis of the articles, special attention was given to (1) articles providing a systematic or comparative overview on the different approaches in transition research; and (2) articles focusing on the spatial embeddedness of sustainable transitions. Therefore, the literature search was thoroughly supplemented in the second stage by the following key words: "spatial transition," "geography of transition," "space," "spatial concepts" or "spatial conceptualization." The selected articles were examined and analysed by using a qualitative content analysis.

This paper is structured as follows. Section 2 focuses on sustainability transition research. It describes the different understandings, goals and methodologies of transition approaches (Section 2.1) and shows that sustainability transition approaches lack the spatial dimensions to facilitate or promote transitions in urban and rural areas (Section 2.2). The following section (Section 2.3) then tackles different understandings of space (physical, socio-cultural, relational). It emphasizes how important a clear differentiation of space as a concept is for the broader understanding and embeddedness of sustainability transitions. Section 3 develops conceptual perspectives wherein space or spatial conceptualizations can provide added value for sustainability transition research in inter- and transdisciplinary modes. These three perspectives include (1) space as a "bridging concept," (2) space as a "normative concept," and (3) space as an "approach to action." This is followed by a critical discussion on the benefits and limits of an explicit space-based approach within transition research (Section 4).

\section{Transition Research and the Spatial Dimension}

Sustainability transitions have received increasing attention in scientific communities in the last decade. Used in different disciplines as synonym of non-linear shifts, the term gains more specific meaning in sustainability transitions research: There, sustainability transitions refer to large-scale societal changes in response to grand societal challenges, serving as a "shorthand for transitions to sustainability" [12] (p. 600). These structural, non-linear systemic changes concern cultural aspects such as shared values, paradigms or discourses, as well as structures in institutions, in economic perspectives and physical surroundings and, of course, practices of societal sub-systems becoming noticeable in changed routines, behaviours or lifestyles $[13,14]$. 


\subsection{Transitions to Sustainable Developments—Goals, Concepts and Methodologies}

Although sustainability transitions can neither be fully determined nor controlled, transitions do have different aspects and phases in common. In general, nonlinearity is seen as one characteristic of the nature of transitions, where transitions are seen as a societal searching and learning process which includes a diversity of actors from different societal spheres (government, markets, civil society), who jointly learn about existing challenges and their root causes, explore social, technical and institutional innovations and change their behaviours [15] (p. 13). The study of transition research supports fundamental change processes in societal systems toward sustainability from a scientific perspective. Another important point characterizing transitions is their embeddedness in dynamics at multiple levels, well-demonstrated in the conceptual framework as multi-level perspective (MLP) [16]. The term "level" is used to distinguish between context (landscape), the dominant regime and alternatives (niches) and does not include a spatial understanding of levels as it refers more to the distribution of innovations in a societal perspective. The third general characteristic of transitions describes innovation itself as a systemic process interacting in a co-evolutionary way, or as stated by Rotmans et al. [13] transitions are "more evolution than revolution." From a systemic point of view, transitions do not follow linear causalities but are continuously developing through interaction with an initial change [12] (p. 608), [16].

Loorbach et al. [12] as well as Schneidewind/Augenstein [17], with little variation, identify three different understandings or schools of transition research with different foci. These foci are dealt by different disciplines with varying epistemological perspectives, changing methodologies and differing conceptual frameworks. They are known as socio-technical understanding (a), the socio-institutional approach (b) and socio-ecological thinking (c).

(a) The roots of transition research lay in socio-technical understanding, the analysis of socio-technical niches and innovation diffusion. The need for socio-technical understanding often starts from new technologically feasible solutions in infrastructure and technologies, such as in the energy or mobility sectors, whose implementation strategies lack a sociological perspective. From an economic approach, it is often argued that innovation needs protected spaces in the "interplay between incumbent regime structures, external landscape pressures and emerging niches" [12] (p. 610), [17] (p. 91).

(b) In terms of disciplines, the socio-institutional approach is based on a wide range of scientific knowledge from economics, law, political science and geography. Research fields are manifold, dealing with actor network theories and questions of governance, discursive approaches and questions of power or research about innovation patterns [17] (p. 90), [18]. These approaches "identify institutionalized cultures, structures and practices as regimes in which transitional change takes place" [12] (p. 610). Existing empirical studies are mostly individual cases of specific sectors or geographical areas with certain problems. A recent shift toward this socio-institutional approach can be observed, especially in combination with the innovative capacity of niches in dominant regimes [19].

(c) Socio-ecological thinking frames transitions within planetary boundaries and the global resilience discussion. Influenced by a more biological, nature-conservative approach, it "examines the way in which this context pushes ecosystems beyond tipping points and planetary boundaries" [12] (p. 612).

Even though these different understandings underscore a great plurality among transition research approaches, three main epistemological approaches can be outlined for different areas of transition research. Each epistemological approach follows its own conceptual framework (overview see [20]), as well as its own foci in terms of transition initiation, analysis or evaluation.

1. Analytical studies "seeks to understand the role of societal forms of agency at different levels and how they might interact with institutional and policy change" [12] (pp. 615, 616). In general, analytical approaches describe the status quo in specific research perspectives, 
in order to (analytically) understand transition processes in specific cases. Conceptual frameworks corresponding to analytical studies are multi-level perspective (MLP) and social niche management (SNM).

2. Evaluative studies aim to understand how transition-oriented policies are set in place and valuate the efficiency and effectiveness of different governance arrangements. "This research deepens our understanding of the role of policy in sustaining existing regimes and advancing sustainability transitions" [12] (p. 616). While analytical studies aim to understand the present situation, evaluative studies are aimed at resuming past activities and discovering their impact on sustainability transitions. The corresponding conceptual framework for evaluative studies is the technological innovations system (TIS).

3. The third epistemological perspective is an experimental one, an approach to check the range of transition research under real-time conditions. "The core idea is that through experiments with new technologies and new socio-technical arrangements, processes of coevolution can be stimulated" [12] (p. 617). Methods such as transitions arenas, scenarios and labs are used to create an open learning atmosphere to test every sort of innovation. The approaches of transition management (TM) or social niche management (SNM) are examples of corresponding conceptual frameworks.

\subsection{Transition Research and the (Missing) Spatial Context}

The abovementioned understandings and approaches to sustainability transition research do not explicitly mention spatial embeddedness-where and how transition processes take place. "Traditionally, the sustainable transitions literature has given little attention to the importance of specificity of transitions in particular places" [21] (p. 7). In fact, most studies of transition research focus on urban settings, as urban areas are defined as nuclei of innovation where niche activities in particular can be stimulated and set in place [1,22-24]. However, findings in the realm of spatial sciences prove that even in rural areas, many different innovations are implemented and discussed under very different circumstances, motivations and with smaller institutional barriers (e.g., in food supply or mobility issues; see, for example, [25]). It seems surprising, then, that especially conceptual frameworks are often less space-sensible and neglect the location-specific implementation of transition processes.

The Geographies of Transition [12,20], a relatively new approach within transition research, aims at providing answers to this spatial blindness. Questions concerning spatial contexts and the general understandings of space are addressed: How far do spatial levels (national, regional, local) matter in order to initiate transition processes? How do local interventions and experiments with niches influence a local context? Do the different approaches to transition activities work in all spatial contexts? And how are transition processes to be implemented in formalized planning and decision contexts?

Scholars like Hansen/Coenen [21] started to implement space as a basic influence on transition research, focusing on place-specificity and questions of scale. From their perspective, localized institutional frameworks should be analysed in order to comprehend the background and potential of individual transition experiments [3], [26] (p. 11). This approach seems to be strongly influenced by the field of economic geography in relation to niche-regime analysis, as it does not address urban and rural settings, shrinking and growing cities, socio-spatial interrelations within neighbourhoods, or regional and national influences [27]. The introduction of questions of scale into sustainability transitions research highlights the importance of the local and regional scales, as "networks of heterogeneous actors are most easily established at the local and regional scale" [21] (p. 15). Hansen/Coenen [21] (p. 15) mention the importance of a geographical proximity for common interactions and experiments. But, in regard to different research approaches dealing explicitly with space and places (like spatial planning, human geography, urbanism, etc.), transition research and the "geographies of transition" research only refer to a small part of the spatial research perspective. In our understanding, the nascent field of transition research could benefit from a more holistic implementation of spatial implications to broaden their knowledge about spatial embeddedness. So how exactly are space and spatial 
concepts analysed and elaborated in spatial sciences and how does this refer to something like a spatial transition research?

\subsection{Exploring Spatial Contexts: Concepts and Approaches}

Space is an omnipresent category with regard to both scientific debates and everyday language. Environmentalists protect selected areas, landscape architects address landscapes as spatial expressions of societal relations to nature, planning disciplines refer to spaces in the form of cities, villages, private or public spaces, etc. In everyday life, people visit existing places or produce new spaces by contributing to the redesign and conversion of their districts. However, a closer look reveals that we are confronted with a variety of terms (such as area, landscape, place or space) and face contested conceptualizations of space. In the following, we aim to make explicit these differences and reflect upon the implications of spatial concepts. By introducing space as Euclidean geometrical space and social space as well as its further development towards relational space, we build on an established differentiation. Thereby, we excursively present the academic work of selected scholars and elaborate epistemic differences between natural, technical and social sciences (see Table 1).

Table 1. Spatial Concepts (own illustration).

\begin{tabular}{|c|c|c|c|}
\hline & Euclidian Geometrical Space & & Social Space \\
\hline Space as ... & Container & Relational & Social \\
\hline Space as research subject & physical & socio-physical & socio-cultural \\
\hline $\begin{array}{l}\text { Space as epistemological } \\
\text { perspective }\end{array}$ & 'natural' environments & Nature Cultures & social relations \\
\hline \multirow[t]{2}{*}{$\begin{array}{l}\text { Space as research } \\
\text { concept }\end{array}$} & naturalistic & dialectic or hybrid & socio-centric \\
\hline & from the outside to the inside & $\begin{array}{l}\text { as inter-relations between } \\
\text { inside and outside }\end{array}$ & from the inside to the outside \\
\hline Related disciplines & $\begin{array}{l}\text { - (neo-classical) economics } \\
\text { - natural and technical sciences }\end{array}$ & $\begin{array}{l}\text { - geography } \\
\text { - urban and regional planning }\end{array}$ & - social and cultural sciences \\
\hline
\end{tabular}

First of all, the understanding of space can follow the idea of Euclidean geometrical space. This concept reflects the modern worldview, mainly influenced by natural sciences. In this vein, space functions as a container, meaning that space is seen as a material, taken-for-granted non-societal but environmental category. Subsequently, space might be empty or not, as "infinite, abstract, unchanging, geometrically definable in terms of a system of coordinates and analytically independent of both time and matter" [28] (p. 139 making reference to [29] (p. 75)). This positivist conceptualization of space has not been completely overcome and is gaining renewed influence in the face of global conflicts and environmental challenges to positivism [30]. Historically, it becomes evident in the Charter of Athens (1933) and has particularly been shaped by German location theory: Based on the works of von Thünen, scholars such as Alfred Weber, Walter Christaller, August Lösch and Walter Isard examined choices of location of agricultural and industrial production, spatial economic order and the development of central places [31]. Today we still witness specific references to this classic work [32] as well as critical examination regarding their influence on Nazi's spatial theory [33]. In particular, geography, which might be characterized as the essential spatial science, has been dominated by the conceptualization of space as a container. Moreover, the concept has strongly influenced (neo-classical) economics based on the epistemology of natural sciences. Here, space is regarded as a distance that needs to be overcome. Even the idea of nation-states in politics reflects the conception of space as a container. Finally, a positivist planning model follows the idea of space as a neutral container [30] (p. 431) and "still has a remarkably powerful resonance today" [10] (p. 624). However, the idea of an absolute objective space determining the social has been fundamentally criticized, as space is not simply about physical territoriality but is created through physical, economic and social networks [4] (p. 68). 
This has been taken up in the discussion on social spaces that replaced essentialist ideas of space by more epistemological approaches. Following the sociological paradigm of explaining the social only by means of the social, these approaches focus on space as a result of social thinking and action. Classical representatives of such approaches include Émile Durkheim and Georg Simmel [34] (pp. 32-35). Their conceptualizations mark a fundamental ontological change in approaching space theoretically as well as empirically: Instead of examining space from the outside (container) to the inside, approaches to social space reflect upon the inside and its implications for the outside. Consequently, space is seen as a social category, emphasizing the political and historical significance and active production of the spatial [28] (p. 140). Ever since the so-called spatial turn in the 1980s [35], these ideas of spatiality as social relation have been taken up (again) so that space is a central category for social and cultural sciences as well as humanities. Moreover, the interest in social space is reflected in and enriched by disciplines such as human geography, urban design and gender studies. Finally, the social production of spatiality is reflected in politics and the effort to spatial governance by means of spatial planning [10], [30] (p. 430). Still, the idea of space as pure socio-spatial relations has been criticized as one-sided because it overemphasizes the social dimension, thereby once again disconnecting the "material" from the "social world." Thus, critics ask for the meaning of physical aspects within socially oriented conceptualizations of space. How does one think of space as material without equating materiality with a container?

Within the discussion on social spaces relational approaches try to answer this question by arguing that objects and space can only be understood in relation to each other and that space does not exist as an entity in and of itself [36-38]. Space is constructed and "has meaning only in relation to the perceptions of actors and to their interests and strategies" [4] (pp. 68-69), meaning that space "does not exist independent of objects and events" but is constructed from the relations between them [30] (p. 431). Thus, space is both a product and process; it is a (material) result of perceived facts and interpretations. Consequently, relational approaches to space neither favour the outside nor the inside but analyse the interface between both. This relational view of space is reflected in various disciplines and seems dominant not only in geography [11] but also in planning theory and practice [10,39] and spatial sociology [38,40]. Many scholars refer to Henri Lefebvre as a central figure for the development of relational spatial concepts. In one of his central works, "The production of space" [41], he introduces a threefold understanding of space in physical, mental and social regards. Lefebvre pays considerable attention to the world of everyday life and people's appropriation of spaces in an urban context, making his work compatible to present problem-centred transdisciplinary approaches. Another famous representative whose view of space and spatiality is "essentially relational" [11] (p. 228) is Doreen Massey. She characterizes space "as the product of interrelations" [42] (p. 9), meaning that "space is a mirror, object and expression of societal power relations and of more or less obvious power struggles" [43].

By trying to overcome the dichotomy between space as a container and social spaces, relational approaches offer promising interpretations of further spatial categories: Contrary to positivist approaches that consider space and place as synonymous, relational approaches understand these two concepts as dialectically related or hybrid and emphasize the socio-cultural and socio-economical functions of places. Thus, relational approaches ask for the actors and their perceptions and interpretations of spatial qualities in the process of place-making [44]. Another important spatial issue is scale. From a relational spatial perspective, scales powerfully structure everyday life but at the same time they are seen as social outcomes [45]. Thus, the "[u]nderstanding of spatiality as matters of fact is combined with its understanding as matters of concern" [30] (p. 438).

Relational thinking further puts emphasis on functional (planning) spaces. These spaces do not necessarily correspond with territorial planning spaces; rather, they represent specific social constructions of space "leading to a proliferation of overlapping and enmeshed functional spaces of planning" [46] (p. 15). Functional spaces involve new and flexible governance arrangements between public, civil and private actors "that may vary according to the project or thematic policy area under 
construction" and that are intended to allow "new thinking to emerge and to provide testing grounds for new policy interventions" [46] (p. 14). This might include housing market areas and commuting areas as well as diverse environmental spaces such as river estuaries, regional parks, bio-regions, renewable energy regions and landscape regions. According to Olesen [47] (p. 151), functional spaces can also be understood or even used strategically to achieve socially relevant objectives such as, for example, sustainable development.

\section{Conceptual Perspectives for a Deeper Understanding of Spatial Transitions Toward Sustainability}

In our point of view, realizing sustainable spaces and places is part of sustainable spatial transition and can only be achieved by inter- and transdisciplinary approaches $[22,48,49]$. Using space or spatial conceptualizations as a problem-oriented concept that encompasses both physical structures and social, cultural and institutional changes might offer conceptual perspectives for a broader understanding of sustainability transitions. Therefore, we will identify the links between sustainable transition approaches and spatial conceptualizations before outlining three conceptual perspectives for a deeper understanding of spatial transitions toward sustainability.

\subsection{Linking Sustainable Transition Approaches and Spatial Conceptualizations to Each Other}

Luque-Ayala et al. [8] (p. 2) summarize how a city transitioning toward low carbon emissions has to study transitions "in their political, geographical and developmental contexts," considering technological-material, societal and institutional changes in cities at different spatial levels. This already indicates that space itself is not a given category but is socially defined, reproduced and redefined (see Section 2.3). "As such, transitions do not simply occur within a certain territorially bounded space (e.g., a country) but emerge out of the tensions created in multi-scalar interactions between spatially distributed actors embedded in multi-level structures with different temporal dynamics" [4] (p. 70). In this relational perspective, space is used to map the uneven geographical landscape of innovation and technical change [2] (p. 969); that is, to explain why innovations and socio-technical changes emerge in one place and not in others (or emerge in a different way). Therefore, transition research recognizes the importance of local contexts and conditions and uses multi-level and multi-scalar governance approaches to relate global, national and local politics to each other (see Sections 2.1 and 2.2). By doing so, sustainable transition approaches become spatially sensitive to the institutional contexts within which socio-technical transition processes evolve and which are highly path-dependent and localized in nature [2] (p. 973). This relational understanding of space and transition allows researchers and policy-makers to promote and govern transition toward sustainability successfully.

However, according to our point of view, sustainability transitions should go beyond this understanding. Looking, for example, at the SDGs of the United Nations it is apparent that achieving most of these goals has direct spatial impacts; this applies above all to clean water and sanitation, affordable and clean energy or sustainable cities and communities that, inter alia, claim for new settlement structures and infrastructures the provision of land for the generation of renewable energies, etc. Space is thus not only an explanatory variable for different institutional or local contexts or for the various speeds of the transition of socio-technical systems. In our understanding, these socio-technical innovations transform space directly and actively but are, at the same time, dependent on space or spatial conditions, meaning that space and spatial conditions also influence the emergence and spill over of technical innovations (see Figure 1). This does not only apply to physical spaces but further embraces-as space is produced and reproduced through human intentions and can be regarded as a structuring element of social processes-relational spatial approaches (see Section 2.3). This allows us to broaden the spatial perspective of transition research as further relevant dimensions are introduced to strengthen the conceptual perspectives of transition approaches. By making the inherent spatial understandings of transition processes explicit, the distinct approaches can be identified, positioned in the research field and research gaps can be described. Using the knowledge from spatial sciences and taking advantage of current knowledge from other scientific fields, transition research is able to 
integrate spatial concerns into its future research perspectives. How this might look will be outlined in the following chapter.

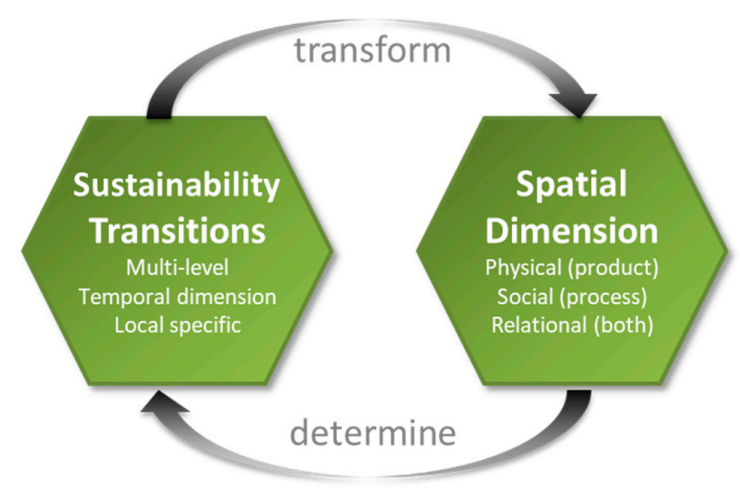

Figure 1. Sustainability transitions and the spatial interface.

\subsection{Conceptual Perspectives to Emphasize Spatial Conceptualization in Transition Research}

We see at least three main perspectives where space or spatial conceptualizations can provide added value for sustainability transition research. These perspectives were developed by concentrating on the characteristics of the spatial conceptualizations presented above and bring together sustainability research, literature of inter- and transdisciplinary approaches, normative visions and their different logics and path dependencies in practice. In this sense, the core characteristics of spatial conceptualisations are peeled out in order to maximise their added value in transition research. These three perspectives include (1) space as a "bridging concept," (2) space as a "normative concept," and (3) space as an "approach to action," which will be explained in the following.

\subsubsection{Space as a "Bridging Concept"}

We can see space as heuristic - that is, able to collect different perspectives on sustainability and transition in order to come to a joint understanding. It is the relational understanding of space that offers a broader perspective to identify, understand and reflect socio-technical transition processes and their interrelations with space and spatial conceptualizations. Space as a "bridging concept" follows an inter- and transdisciplinary perspective, allowing researchers from different fields to come to a joint understanding of certain key concepts and terms. As each approach has its strengths, bridging concepts in general are able to visualize a variety of different approaches without abandoning other approaches, by focusing on specific aspects of a situation (for example, looking at physical spaces). From our point of view, space as a bridging concept is highly beneficial, as sustainability transition approaches and spatial conceptualization have various characteristics in common that allow merging the two approaches successfully:

- Both concepts focus on intentionally designed processes to bring about (socially desired) change. In terms of transition theories, emphasis is put on the adoption of socio-technical innovations, especially those developing out of niches; with regard to (physical) spaces, it is urban or regional planning that determines the different land uses, settlement structures, etc. from a sovereign perspective (city administration as institution). There, these two perspectives on intended change can easily be integrated from a grassroots-level development to an intended change out of public institutions. Additionally, both approaches are following integrated and comprehensive perspectives.

- Both transition processes and urban or regional development processes have a long-term orientation. While transition research emphasizes a co-evaluative development where change can neither be steered nor foreseen, spatial planning focuses more on the steering of intended 
change and prevention of undesired incidents. This future orientation also means that solution approaches and strategies often are non-linear (uncertain), due to social or environmental changes as well as the complex and interrelated challenges that sustainability transitions and spatial conceptualizations face.

- Both theoretical approaches offer actor-centred approaches and actor collaborations on different spatial levels. These approaches follow the premise that actions are always based on values, power relations, norms and the complex interactions between different actors and actor groups, value driven interests and demands concerning time and space that make transitions possible and real. In this regard, transition processes as well as space can always be seen as result of a negotiation process of a given society. For more detail, multi-level and multi-scalar perspectives are used in both approaches, making it possible to combine them.

Space as a bridging concept can be seen as an inter- and transdisciplinary umbrella concept, recognizing the various transition research approaches, addressing the missing spatial questions of transition research (i.e., its partial spatial blindness) and providing perspectives for a deeper understanding of spatial transitions. It can be seen as an inter- and transdisciplinary bridge to compare research approaches and joint systemic findings. Figure 2 shows important questions that are crucial for space as a bridging concept, including the already mentioned physical and social, in particular relational space concepts.

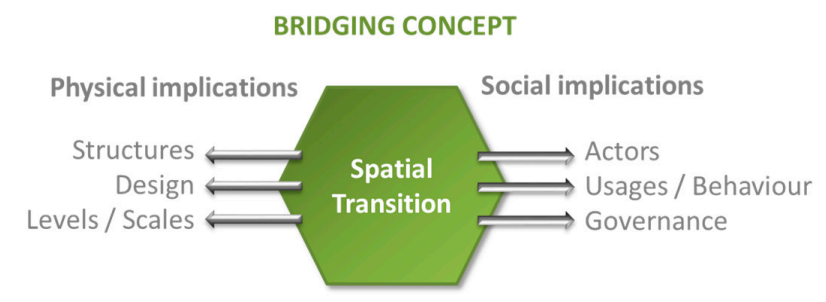

Figure 2. Space as a bridging concept.

\subsubsection{Space as a "Normative Concept"}

In general, normative concepts make claims about how things should be and how to value them in order to give instructions and guiding principles to do the "right" thing. Space as a normative concept tries to provide solutions related to how a transition toward sustainability should look in different spatial arrangements, for example, in a city, a region or a neighbourhood. Based on a space-sensible integrative perspective, space as a normative concept provides guidelines and visions about how different sectoral transition perspectives have to be integrated sustainably, for example, how sustainable mobility can be integrated in sustainable energy supply, sustainable living conditions or sustainable demographic change. Another important question regarding space as a normative concept is (in)equality. For sustainability claims for intra- and intergenerational justice, sustainability transitions need to map social inequalities and their spatial causes and effects (e.g., social justice within the North-South context, gender justice, justice regarding future generations). However, besides visions on the design of a built environment and its physical structures, it is further necessary to provide visions on the process design (Figure 3): Which actors have to be involved? How might sectoral barriers to collaboration and the limitations arising from them overcome? Which governance arrangements are needed to achieve socio-spatial sustainability?

Space as a normative concept is basically linked to the disciplines of architecture, urban design, urban and regional planning, urban and rural sociology and spatially oriented gender studies. These disciplines offer a broad range of instruments, such as urban and regional land-use plans and programs, urban visions or rural development concepts or spatial models that can help stimulate public discourses on the objectives of sustainable development and that, at the same time, provide orientation and standards for individual and collective actions. 


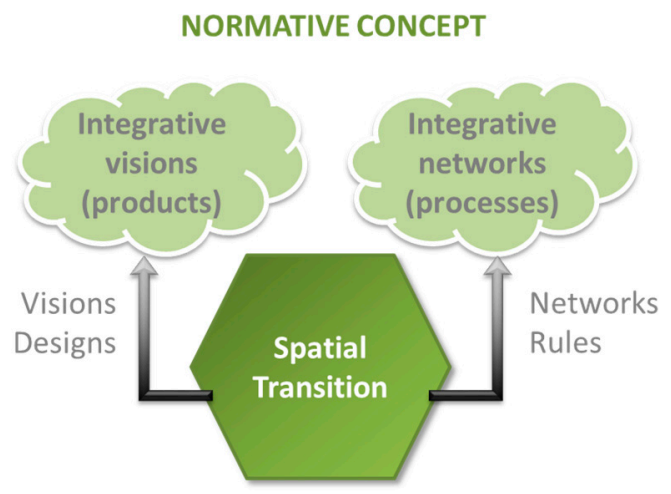

Figure 3. Space as a normative concept.

\subsubsection{Space as an "Approach to Action"}

Spaces can also be regarded as an "approach to action," that is, they provide the spatial basis for sustainable transition [49]. This includes, first of all, the transition of physical spaces by planners, architects and geographers. This understanding particularly focuses on the reconfiguration of technical infrastructures (e.g., the construction of new infrastructures for energy transmission, etc.) and urban quarters (car-free quarters, climate-friendly cities, etc.) as the adaptation of physical structures, functional spaces, settlement patterns and infrastructures, too. However, sustainable spatial transition is not only about designing sustainable physical spaces and places. In contrast, space is both product and process at the same time, emphasizing the socio-cultural and socio-economic functions of places. Seen in this light, space is, secondly, a key dimension to promote "active collaboration among diverse stakeholders, integrating different perspectives and bodies of knowledge and expertise and stimulating experimentation with different solutions and approaches" [49] (p. 4). The explicit focus on collaboration might have several benefits for sustainability transition: (1) to increase the acceptance for planned or necessary interventions and (technical) innovations in physical spaces; (2) to test whether proposed (technical) solutions correspond to concerned people or "social milieus"; and (3) to ensure that individuals or groups can "assimilate" and define space, finally adopting or designing it according to their ideas (see Figure 4). Additionally, sustainable spatial transition encompasses economic, social, cultural and institutional changes [22]. This means that space, thirdly, also offers the base from which to analyse local or specific contexts, institutional thickness and also the relations between different scales (see Sections 2.1 and 3.1). This dedicated inter- and transdisciplinary aspect allows comprehension of the emergence and potentials of (technical) innovations in a certain (local) context, including transition experiments and governance approaches.

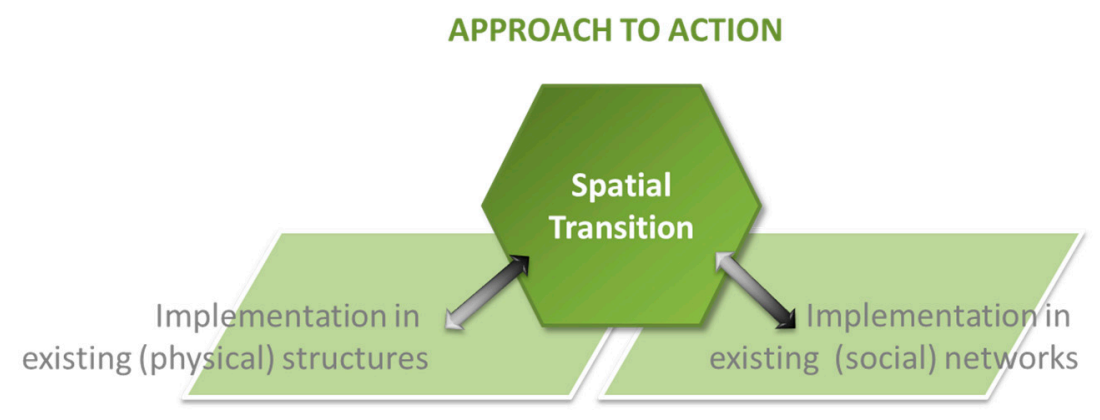

Figure 4. Space as an approach to action.

One approach to foster sustainable spatial transitions is through the temporary, flexible and experimental use of vacant land. Instead of viewing vacant land as a problem that planners try to 
develop accordingly in line with formal land-use plans, vacant land could also be considered as a resource or have the potential for unorthodox and innovative uses [50] (p. 3). This creates room to manoeuvre for politicians, public actors, economic actors or civil-society actors, allowing or facilitating innovative and often experimental solutions in a spatial context. These temporary and experimental uses of brownfield sites can, on the one hand, pursue ecological transition goals (e.g., by leaving brownfield sites to run wild, by "creating" open or green spaces or by keeping brownfields free of any development to maintain their functions as areas of cold-air production, fresh air lanes, etc.) but also social transition aims. Regarding the latter, vacant land and brownfield sites might be considered from inhabitants and concerned groups to be for intermediate (social) uses, for example, for urban gardening or for recreation or sports. It is important here that the local actors have the opportunity to play an active role in the process, can develop their own (spatial) ideas and can-in comparison to the status quo-contribute to a sustainable spatial transition via experimental and innovative uses or solutions.

Another approach to frame the transition of (physical and social) spaces can be found in design-based strategies. Design thinking combines people's desires and needs with what is technological and scientifically feasible, physically relevant and economically viable [51]. In this sense, design-based strategies can actively be used to contribute to the sustainable transition of cities and regions. By pursuing a solution-based approach [52,53], design thinking - similar to the temporary and flexible use of vacant land-is strongly related to material and social spaces. In this context, various strategies and methods are combined, based on criteria such as practicality, appropriateness, experimental design, empathy and cultural fit [54], aiming at aesthetic, functional, emotional and strategic qualities. Design-based strategies are, for example, used to design airports and touristic strategies but also to develop new and sustainable neighbourhoods. In this way, this approach has the potential to consider the physical space, the social needs and the social interpretations of space and (technical and cultural) innovations at the same time.

\section{Discussion}

As pointed out above, the ongoing debate about sustainability transitions and its pathways toward an implementation of sustainable living conditions lacks space as a crucial perspective asking how specific places have to facilitate, prepare, promote or implement a more sustainable future. This theoretical and empirical gap increases factual challenges on the local and regional level, but, in our understanding, inter- and transdisciplinary sustainability sciences will unavoidably be confronted with different conceptualizations of space. As deeper investigation in the field of spatial sciences has clarified, space has been-and continues to be-conceptualized in manifold ways. Thus, sustainability transition research is unavoidably confronted with different, partly contradictory spatial conceptualizations. Relational approaches to space-which are necessarily more than an addition of container and pure social spatial concepts-seem promising to focus on the interrelations between space as a structure and space as a social process. In view of the above, we developed three perspectives in order to elaborate the interface between sustainability transition and space. These include space as a bridging concept, space as a normative concept and space as an approach to action.

In conclusion, the benefits and limits of an explicit space-based approach within sustainability transition research need to be critically discussed. We argue that the field of sustainability transition research might take the chance and use the knowledge from spatial sciences with regard to both theoretical and empirical challenges to develop a broader understanding of transition and to embed transition processes in spatial contexts. Regarding this interface, at least three consequences can be derived.

\subsection{Paradigmatic Consequences}

We address sustainability transition research as inter- and transdisciplinary sciences. Thus, different disciplinary perspectives as well as contributions from practice form particular understandings of the 
problem, formulate research questions, choose methods, etc. Space as a bridging concept (see Section 3.2) strengthens this inter- and transdisciplinary perspective by making it more explicit. The paradigmatic consequence of this insight is that sustainability transition research will rather succeed as a mode 2 science, which is application-oriented and transdisciplinary.

\subsection{Epistemological Consequences}

Engagement with different spatial concepts has shown that there is a need to overcome the reductionist perspectives on space as either "natural" environments or social relations. Inter- and transdisciplinary sustainability transition research cannot go along with a disciplinary dichotomization where physical space is handed over to natural and technical sciences, whereas social sciences deal with social relations. To overcome the still dominant perspective of space as a container does not mean to ignore or forget about spatial materiality. This materiality must not be confused with a non-societal natural or built environment determining the conditions for the social in the sense of "planetary boundaries." The epistemological consequence of this insight is that sustainability transition research needs to reflect (all) its central categories (nature, technic, etc.) with respect to epistemological reductionisms.

\subsection{Methodological and Methodical Consequences}

Taking space into consideration links up theoretical and empirical intentions in terms of methodology and methods. The methodological consequences are about matching the requirements that arise out of the relational spatial approach by capturing interrelations between the material and the social world and by addressing space simultaneously as a product and a process. To meet these requirements, a variety of methods are needed. These are quantitative and qualitative methods, scenario technics, modelling, etc. The methodological and methodical consequence of this insight is that sustainability transition research needs to elaborate an ambitious methodological program and bring together diverse methods.

After all, we claim for nothing more than a "spatial turn" in sustainability transition research. Following Malpas [11] (p. 227), it is "imperative that the concept of space [is] more carefully and critically examined." This is not an academic goal in itself but offers conceptual perspectives in order to promote inter- and transdisciplinary dialogues and discourses and to reflect upon political implications of scientific research and vice versa with regard to "our common future."

Author Contributions: All authors contributed equally to the conceptualization of the article, the research and analysis of the literature, the writing of the draft paper, the review and editing of the paper and the visualization.

Funding: The publication of this article was funded by the Open Access Fund of the Leibniz Universität Hannover.

Conflicts of Interest: The authors declare no conflict of interest.

\section{References}

1. Frantzeskaki, N.; Broto, V.C.; Coenen, L.; Loorbach, D. Urban Sustainability Transitions. The Dynamic and Opportunities of Sustainability Transitions in Cities. In Urban Sustainability Transitions; Frantzeskaki, N., Broto, V.C., Coenen, L., Loorbach, D., Eds.; Routledge: New York, NY, USA, 2017; pp. 1-22. ISBN 978-0-415-78418-4.

2. Coenen, L.; Benneworth, P.; Truffer, B. Toward a Spatial Perspective on Sustainability Transitions. Res. Policy 2012, 41, 968-979. [CrossRef]

3. Coenen, L.; Truffer, B. Places and Spaces of Sustainability Transitions: Geographical Contributions to an Emerging Research and Policy Field. Eur. Plan. Stud. 2012, 20, 367-374. [CrossRef]

4. Raven, R.P.J.M.; Schot, J.W.; Berkhout, F. Space and Scale in Socio-Technical Transitions. Environ. Innov. Soc. Trans. 2012, 4, 63-78. [CrossRef]

5. Smith, A.; Vo $\beta$, J.-P.; Grin, J. Innovation Studies and Sustainability Transitions: The Allure of a Multi-Level Perspective and its Challenges. Res. Policy 2010, 39, 435-448. [CrossRef] 
6. Truffer, B.; Murphy, J.; Raven, R.P.J.M. The Geography of Sustainability Transitions: Contours of an Emerging Theme. Environ. Innov. Soc. Trans. 2015, 17, 63-72. [CrossRef]

7. Wolfram, M. Stadt, Wandel, Nachhaltigkeit: Zur Konvergenz von Urbanistik und Transitionsforschung. PND Online 2014, II, 1-11.

8. Luque-Ayale, A.; Marvin, S.; Bulkeley, H. Introduction. In Rethinking Urban Transitions: Politics in the Low Carbon Cities; Luque-Ayale, A., Marvin, S., Bulkeley, H., Eds.; Routledge: Abingdon, UK, 2018; pp. 2-12. ISBN 9781138057401.

9. Godlove, T.F. Is "Space” a Concept? Kant, Durkheim, and French Neo-Kantianism. J. Hist. Behav. Sci. 1996, 32, 441-455. [CrossRef]

10. Graham, S.; Heleay, P. Relational Concepts of Space and Place: Issues for Planning Theory and Practice. Eur. Plan. Stud. 1999, 7, 623-646. [CrossRef]

11. Malpas, J. Putting space in Place: Philosophical Topography and Relational Geography. Environ. Plan. D Soc. Space 2012, 30, 226-242. [CrossRef]

12. Loorbach, D.; Frantzeskaki, N.; Avelino, F. Sustainability Transitions Research: Transforming Science and Practice for Societal Change. Annu. Rev. Environ. Resour. 2017, 42, 599-626. [CrossRef]

13. Rotmans, J.; Kemp, R.; van Asselt, M. More Evolution Than Revolution: Transition Management in Public Policy. Foresight 2001, 3, 15-31. [CrossRef]

14. Grin, J.; Rotmans, J.; Schot, J. Transitions to Sustainable Development. New Directions in the Study of Long Term Transformative Change; Routledge: New York, NY, USA; London, UK, 2010; ISBN 9780415876759.

15. Wittmayer, J.; Hölscher, K. Transformationsforschung: Definitionen, Ansätze, Methoden; Umweltbundesamt, Ed.; Umweltbundesamt: Dessau-Roßlau, Germany, 2017; ISBN 18624359.

16. Jørgensen, U. Mapping and Navigating Transitions-Multi-Level Perspective Compared with Arenas of Development. Res. Policy 2012, 41, 996-1010. [CrossRef]

17. Schneidewind, U.; Augenstein, K. Three Schools of Transformation Thinking: The Impact of Ideas, Institutions, and Technological Innovation on Transformation Processes. GAIA 2016, 25, 88-93. [CrossRef]

18. Avelino, F.; Grin, J.; Pel, B.; Jhagroe, S. The Politics of Sustainability Transitions. J. Environ. Policy Plan. 2016, 18, 557-567. [CrossRef]

19. Ehnert, F.; Frantzeskaki, N.; Barnes, J.; Borgström, S.; Gorissen, L.; Kern, F.; Strenchock, L.; Egermann, M. The Acceleration of Urban Sustainability Transitions: A Comparison of Brighton, Budapest, Dresden, Genk, and Stockholm. Sustainability 2018, 10, 612. [CrossRef]

20. Markard, J.; Raven, R.; Truffer, B. Sustainability Transitions: An Emerging Field of Research and its Prospects. Res. Policy 2012, 41, 955-967. [CrossRef]

21. Hansen, T.; Coenen, L. The Geography of Sustainability Transitions: Review, Synthesis and Reflections on an Emergent Research Field. Environ. Innov. Soc. Trans. 2015, 17, 92-109. [CrossRef]

22. Ernst, L.; de Graaf-Van Dinther, R.E.; Peek, G.J.; Loorbach, D.A. Sustainable Urban Transformation and Sustainability Transitions: Conceptual Framework and Case Study. J. Clean. Prod. 2016, 112, 2988-2999. [CrossRef]

23. Nevens, F.; Frantzeskaki, N.; Loorbach, D. Urban Transition Labs: Co-Creating Transformative Action for Sustainable Cities. J. Clean. Prod. 2013, 50, 111-122. Available online: https:/ / www.researchgate.net/ publication/260137056_Nevens_F_Frantzeskaki_N_Loorbach_D_Gorissen_L_Urban_Transition_Labs_ co-creating_transformative_action_for_sustainable_cities_Journal_of_Cleaner_Production_50_111-122 (accessed on 16 April 2018). [CrossRef]

24. Wolfram, M. Urban Planning and Transition Management: Rationalities, Instruments and Dialectics. In Co-Creating Sustainable Futures. A Primer on Applying Transition Management in Cities; Frantzeskaki, N., Hoelscher, K., Bach, M., Avelino, F., Eds.; Springer: Dordrecht, The Netherlands; Berlin, Germany, 2016; ISBN 9783319692739.

25. Esparcia, J. Innovation and Networks in Rural Areas: An Analysis from European Innovative Projects. J. Rural Stud. 2014, 34, 1-14. [CrossRef]

26. Coenen, L.; Raven, R.; Verbong, G. Local Niche Experimentation in Energy Transitions: A Theoretical and Empirical Exploration of Proximity Advantages and Disadvantages. Technol. Soc. 2010, 32, 295-302. [CrossRef]

27. Boschma, R.; Coenen, L.; Frenken, K.; Truffer, B. Toward a Theory of Regional Diversification: Combining Insights from Evolutionary Economic Geography and Transition Studies. Reg. Stud. 2017, 51, 31-45. [CrossRef]

28. Bondi, L. Troubling Space, Making Space, Doing Space. Group Anal. 2005, 38, 137-149. [CrossRef] 
29. Smith, N.; Katz, C. Grounding Metaphor: Towards a Spatialized Politics. In Place and the Politics of Identity; Keith, M., Pile, S., Eds.; Routledge: London, UK; New York, NY, USA, 1993; pp. 67-83. ISBN 0415090083.

30. Davoudi, S. The Legacy of Positivism and the Emergence of Interpretive Tradition in Spatial Planning. Reg. Stud. 2012, 46, 429-441. [CrossRef]

31. Beckmann, M.J.; Bröcker, J.; Chaloupek, G.; Kurz, H.D.; Nellinger, L.; Rieter, H.; Schmidt, K.-H.; Todt, H.; Trautwein, H.-M. Studien zur Entwicklung der ökonomischen Theorie XXIX. In Schriften des Vereins für Socialpolitik; Band 115; Duncker \& Humblot: Berlin, Germany, 2014.

32. Sonis, M. Central Place Theory after Christaller and Lösch. Some Further Explorations. In Memory of August Lösch, 15 October 1906-30 May 1945. In Proceedings of the 45th Congress of the European Regional Science Association (ERSA): Land Use and Water Management in a Sustainable Network Society, Amsterdam, The Netherlands, 23-27 August 2005.

33. Barnes, T.J.; Minca, C. Nazi Spatial Theory: The Dark Geographies of Carl Schmitt and Walter Christaller. Ann. Assoc. Am. Geogr. 2013, 103, 669-687. [CrossRef]

34. Löw, M.; Sturm, G. Raumsoziologie. In Handbuch Sozialraum; Kessel, F., Reutlinger, C., Maurer, S., Frey, O., Eds.; Springer: Wiesbaden, Germany, 2005; pp. 31-48.

35. Bachmann-Medik, D. Cultural Turns: New Orientations in the Study of Culture; De Gruyter: Berlin, Germany; Boston, MA, USA, 2016; ISBN 9783110402971.

36. Jones, M. Phase Space: Geography, Relational Thinking, and Beyond. Prog. Hum. Geogr. 2009, 33, 487-506. [CrossRef]

37. Jones, M. Limits to Thinking Space Relationally. Int. J. Law Context 2010, 6, 243-255. [CrossRef]

38. Löw, M. The Sociology of Space: Materiality, Social Structures, and Action; Translated from the German by Donald Goodwin; Palgrave Macmillan: New York, NY, USA, 2016; ISBN 9781137487711.

39. Jessop, B.; Brenner, N.; Jones, M. Theorizing sociospatial relations. Environ. Plan. D Soc. Space 2008, 26, 389-401. [CrossRef]

40. Krämer-Badoni, T.; Kuhm, K. (Eds.) Die Gesellschaft und ihr Raum. Raum als Gegenstand der Soziologie. 2003. Available online: https:/ /d-nb.info/968756549/04 (accessed on 4 June 2018).

41. Lefebvre, H. The Production of Space; Wiley-Blackwell: Oxford, UK, 1991; ISBN 9780631181774.

42. Massey, D. For. Space; Sage: London, UK; Thousand Oaks, CA, USA; New Delhi, India, 2005; ISBN 9781412903615.

43. Hunig, S.; Mölders, T.; Zibell, B. Gender, Space and Development. An Introduction to Concepts and Debates. In Gendered Approaches to Spatial Development in Europe-Perspectives, Similarities and Differences; Zibell, B., Damyanovic, D., Sturm, U., Eds.; Routledge: Abingdon, UK, 2018.

44. Healey, P.; de Magelhaes, C.; Madanipour, A. Assessing Institutional Capacity for City Centre Regeneration: Newcastle's Grainger Town. In Urban Governance, Institutional Capacity and Social Milieux; Cars, G., Healey, P., Madanipour, A., de Magalhaes, C., Eds.; Ashgate: London, UK, 2002; pp. 45-64. ISBN 9780754619390.

45. Swyngedouw, E. Globalisation or "Glocalisation"? Networks, Territories and Rescaling. Camb. Rev. Int. Aff. 2004, 17, 25-48. [CrossRef]

46. Allmendinger, P.; Haughton, G.; Knieling, J.; Othengrafen, F. Soft Spaces, Planning and Emerging Practices of Territorial Governance. In Soft Spaces in Europe: Re-Negotiating Governance, Boundaries and Borders; Allmendinger, P., Haughton, G., Knieling, J., Othengrafen, F., Eds.; Routledge: Abingdon, UK, 2015; pp. 3-21. ISBN 9781138783980.

47. Olesen, K. Strategic Spatial Planning in Transition: A Case Study of Denmark. Ph.D. Thesis, Aalborg University, Aalborg, Denmark, September 2011.

48. Bergmann, M.; Jahn, T.; Knobloch, T.; Krohn, W.; Pohl, C.; Schramm, E. Methods for Transdisciplinary Research: A Primer for Practice; Campus: Frankfurt am Main, Germany, 2012; ISBN 9783593396477.

49. McCormick, K.; Anderberg, S.; Coenen, L.; Neij, L. Advancing Sustainable Urban Transformation. J. Clean. Prod. 2013, 50,1-11. [CrossRef]

50. Németh, J.; Langhorst, J. Rethinking Urban Transformation: Temporary Uses for Vacant Land. Cities 2013, 40, 143-150. [CrossRef]

51. Brown, T. Design Thinking. Harv. Bus. Rev. 2008, 86, 84-92. Available online: http://5a5f89b8e10a225a44acccbed124c38c4f7a3066210c073e7d55.r9.cf1.rackcdn.com/files/pdfs/IDEO_HBR_DT_08.pdf (accessed on 24 April 2018). [PubMed] 
52. Brown, T.; Wyatt, J. Design Thinking for Social Innovation. SSIR 2010, 8, 30-35. Available online: https: //ssir.org/images/articles/2010WI_Features_WyattBrown_New.pdf (accessed on 22 April 2018). [CrossRef]

53. Cross, N. Design Thinking: Understanding How Designers Think and Work; Berg Publishers: Oxford, UK; New York, NY, USA, 2011; ISBN 9781847886361.

54. Owen, C. Design Thinking: Notes on its Nature and Use. Des. Res. Q. 2006, 2, 16-28. Available online: https:/ / www.id.iit.edu/wp-content/uploads/2015/03/Design-thinking-notes-on-its-nature-anduse-owen_desthink071.pdf (accessed on 24 April 2018).

(C) 2018 by the authors. Licensee MDPI, Basel, Switzerland. This article is an open access article distributed under the terms and conditions of the Creative Commons Attribution (CC BY) license (http:/ / creativecommons.org/licenses/by/4.0/). 